\title{
Masturbation: Breaking the Silence
}

There is not one single solution to stop this epidemic. If [there] were, we would have ... found it a long time ago.-Peter Piot, former executive director of UNAIDS ${ }^{1}$

"It saved me." This emphatic, unrestrained declaration was the response of our young black South African driver to my query about masturbation, as we passed the time discussing HIV en route to Soweto on an AIDS-related field trip. Although he had a steady girlfriend, he earnestly believed that the sexual outlet provided through masturbation enabled him to avoid seeking multiple partners, which would have exposed him to HIV infection.

$\mathrm{He}$ is far from alone. Masturbation is very common. In a recent representative survey of the British population, $73 \%$ of men and $37 \%$ of women said they had masturbated in the past four weeks. ${ }^{2}$ And while we tend to connect masturbation with adolescence, among Americans aged 57-64, $63 \%$ of men and $32 \%$ of women reported masturbating in the 12 months before they were interviewed. ${ }^{3}$ Evidence from developing countries is scant. However, a representative survey from urban China found that masturbation was common, albeit at lower levels than these. ${ }^{4}$ In a small study in Zimbabwe, male and female student nurses and midwives commonly reported having ever masturbated, ${ }^{5}$ and the practice was also found to be fairly common among unmarried adolescents in Tanzania. ${ }^{6}$ That masturbation is widely practiced is not surprising. Though not the most fulfilling means of sexual expression, it has the distinct advantages of being pleasurable, accessible, expeditious, inexpensive and safe.

But unlike our driver, who discussed masturbation so readily, as a global health community we too often obediently bow to the social taboo that masturbation is a topic to be avoided. For example, UNAIDS' extensive Practical Guidelines for Intensifying HIV Prevention does not even mention masturbation (though it is alluded to in passing, lumped with abstinence into the phrase "abstinence from penetrative sex"). ${ }^{7}$ Thus, as a professional community, we are neglecting a safe and widely acceptable alternative to risky sex that could play a significant role in the fight against not only AIDS, but other STIs and even unwanted pregnancy.

Yet if masturbation is already commonly practiced, what is to be gained by addressing it more openly in public health policy and programs? For one thing, masturbation is encumbered by many myths, especially in the developing world. For example, a common myth asserts that losing semen saps men of energy and vital fluids. ${ }^{8}$ Also, the widespread taboo against even talking about masturbation reinforces the idea that there is something wrong with it. As public health professionals, we need to transcend this social taboo and position masturbation as a safe-sex alternative that complements other preventive approachessuch as partner limitation, condoms, male circumcision, abstinence, avoiding commercial and cross-generational sex, and promoting more fulfilling primary relationships.

Moreover, masturbation (including mutual masturbation) has particular merit in a number of specific HIV intervention arenas. For example, the long-term physical separation of partners, especially for work, is a significant factor in the initiation of multiple sexual partnerships by both men and women. ${ }^{9}$ In the age of cell phones, the shared intimacy of telephone sex between separated partners might not only forestall the impulse to have secondary partners, but even help maintain a primary relationship.

Another such arena is the prevention of HIV transmission between serodiscordant partners. Currently, the primary options for such couples are condoms and abstinence, though vague options such as "alternative forms of sexual expression" are sometimes mentioned. ${ }^{10}$ At some point, antiretrovirals for prevention may be another option. However, neither condom use nor abstinence is very popular among partners in long-standing relationships, and couple dissolution among serodiscordant partners is common. ${ }^{11}$ The alternative of mutual masturbation might not only reduce the frequency of unprotected genital sex, but help preserve a couple's relationship.

Easing the abstinence recommendation for the period after male circumcision is another arena in which masturbation may serve a public health need. Currently, men are advised to remain abstinent (from masturbation as well as from intercourse) for six weeks after the procedure. ${ }^{12}$ The prospect of six weeks of total abstinence is often daunting and serves as a disincentive for men to undertake the procedure. The rationale for the recommendation of abstinence is to maximize wound healing and reduce potential HIV transmission during that time. But masturbation itself carries no risk of transmission. Moreover, healing is complete for the large majority of men within 30 days, ${ }^{13}$ and it is doubtful that temperate masturbation would substantially delay healing in any case. If men were told they could masturbate, say, a month after the circumcision (preferably with a suitable lubricant), it might make the procedure more attractive to potential recipients, as well as reduce the chance that they might violate instructions and have coital sex early.
By James D. Shelton

James D. Shelton lives in Boyds, MD, USA. 
Finally, masturbation could help reduce the likelihood of HIV transmission during pregnancy and in the postpartum period, when such prevention is especially important; one major study suggested that women are biologically more susceptible to HIV infection when pregnant. ${ }^{14}$ Because coital frequency often declines during pregnancy and the postpartum period, male partners may have a tendency to seek other partners, ${ }^{15}$ thus exposing the pregnant woman to increased risk of infection. Furthermore, a new infection during pregnancy or breastfeeding poses a substantial risk of maternal-to-child transmission because of the high viral loads that occur when the pregnant woman is newly infected. ${ }^{16}$ For these reasons, including both individual and mutual masturbation as prevention options in pregnancy-centered HIV programs could help prevent infection for both mother and child.

The public health community's reluctance to discuss masturbation may have contributed to the dearth of research and evaluation addressing it, especially in the developing world. We need more research, including research to improve our understanding of how programs can incorporate the message that masturbation can be a useful element of safer-sex behavior. Of course, we must be tactful and cognizant of the social sensibilities regarding masturbation, especially in the diverse cultures in which HIV prevention is needed. And programmatically, masturbation should be included along with other prevention approaches in a complementary fashion. As committed, research-driven professionals, we must use every reasonable available tool in the fight against HIV. We cannot afford to continue to ignore this common human behavior when people's lives are at stake. In good conscience, we must be silent about masturbation no longer.

\section{REFERENCES}

1. Kaiser Family Foundation, The search for an HIV vaccine: where are we, where are we going, and how can we get there faster, panel discussion at the 18th International AIDS Conference, Vienna, Austria, July 18, 2010, <http://globalhealth.kff.org/ /media/Images/ AIDS2010/Support\%20Files/The\%20Search\%20for\%20an\%20HIV\%2 OVaccine\%20Transcript.pdf>, accessed Aug. 27, 2010.

2. Gerressu M et al., Prevalence of masturbation and associated factors in a British national probability survey, Archives of Sexual Behavior,
2008, 37(2):266-278

3. Lindau ST et al., A study of sexuality and health among older adults in the United States, New England Journal of Medicine, 2007, 357(8):762-774.

4. Das A, Parish WL and Laumann EO, Masturbation in urban China, Archives of Sexual Behavior, 2009, 38(1):108-120.

5. Verkuyl DA, Self reported sexual and reproductive behavior of male and female student nurses and midwives in Bulawayo, Central African Journal of Medicine, 2000, 46(12):325-329.

6. Kazaura MR and Masatu MC, Sexual practices among unmarried adolescents in Tanzania, BMC Public Health, 2009, Vol. 9, Art. 373, <http://www.biomedcentral.com/1471-2458/9/373>, accessed July $30,2010$.

7. Joint United Nations Programme on HIV/AIDS (UNAIDS), Practical Guidelines for Intensifying HIV Prevention: Towards Universal Access, 2007, <http://data.unaids.org/pub/Manual/2007/20070306_ Prevention_Guidelines_Towards_Universal_Access_en.pdf $>$, accessed May 28, 2010

8. Money J, Prakasam KS and Joshi VN, Semen-conservation doctrine from ancient Ayurvedic to modern sexological theory, American Journal of Psychotherapy, 1991, 45(1):9-13

9. Lurie MN et al., Who infects whom? HIV-1 concordance and discordance among migrant and non-migrant couples in South Africa, AIDS, 2003, 17(15):2245-2252

10. Bunnell R et al., Changes in sexual behavior and risk of HIV transmission after antiretroviral therapy and prevention interventions in rural Uganda, AIDS, 2006, 20(1):85-92.

11. Porter L et al., HIV status and union dissolution in Sub-Saharan Africa: the case of Rakai, Uganda, Demography, 2004, 41(3):465-482.

12. World Health Organization and UNAIDS, Operational Guidance for Scaling Up Male Circumcision Services for HIV Prevention, 2008 , $<$ http://www.malecircumcision.org/programs/documents/MC_ OpGuideFINAL_web.pdf>, accessed May 28, 2010.

13. Mehta SD et al., Does sex in the early period after circumcision increase HIV-seroconversion risk? Pooled analysis of adult male circumcision clinical trials, AIDS, 2009, 23(12):1557-1564

14. Gray RH et al., Increased risk of incident HIV during pregnancy in Rakai, Uganda: a prospective study, Lancet, 2005, 366(9492):11821188

15. Lawoyin TO and Larsen U, Male sexual behaviour during wife's pregnancy and postpartum abstinence period in Oyo State, Nigeria, Journal of Biosocial Science, 2002, 34(1):51-63.

16. Lockman S and Creek T, Acute maternal HIV infection during pregnancy and breast-feeding: substantial risk to infants, Journal of Infectious Diseases, 2009, 200(5):667-669.

Author contact:sheltonjd@comcast.net 